\section{Mr. Fan and Mr. Xin, et al reply}

To the Editor:

We thank Liu, et $a l^{1}$ for their comments on our recent study, "Male sexual dysfunction and ankylosing spondylitis: a systematic review and metaanalysis"2.

To derive a more precise estimation of the sexual function and its clinical correlations in men with ankylosing spondylitis (AS), the metaanalysis was performed. Sexual dysfunction was currently established on the basis of 5 domains: erectile function (EF), orgasmic function (OF), sexual drive (SD), intercourse satisfaction (IS), and overall satisfaction (OS). The 5 domains formed the main focus of the object and both metaanalysis and regression analysis were all analyzed in our study. In metaanalysis, case and control groups' data must be provided; however, it will not affect the results in regression analysis if the control group's data cannot be provided. This is why the metaanalysis was performed in only 5 or 6 studies; while 11 studies were included in the research in our study, the others were only provided in regression analysis. In addition, the effect size was measured by standardized mean differences, and therefore it also does not affect the results if the included studies' results are in different units.

In EF domain, there are 6 studies. Begg funnel plot and Egger test were tested and found no evidence of publication bias. However, like OF and IS, there are only 5 studies - too few to conduct funnel plot analysis and Egger tests, and we cannot be sure whether there is publication bias. Therefore, we wrote the sentence that it is possible that there is publication bias in the metaanalysis study in the discussion.

The question concerning the data of $\mathrm{Xu}$, et $a l^{3}$ and Pirildar, et $a l^{4}$ is a very good one. When we found the data in 2 papers, we also doubted they may be in the same research. We tried to contact the author of the last paper, but could not. Considering that the countries (Turkey and China) and the number of participants are different, eventually we put them as 2 independent papers. But the sensitivity analysis was performed in our metaanalysis, and the results were not changed in each domain of the IIEF. Therefore, even if the 2 papers were the same, the results were still right.
As Liu, et al show, metaanalysis is a useful approach to assess and synthesize the results of pertinent studies to draw conclusions; however, the theories and methods in this case were complex and profound. And the authors should learn more about how to go to practice problems from the statistical professionals. In any case, we thank the authors for carefully reading our article. The problem of sexual function and its clinical correlations in men with AS should be further investigated in future prospective cohort studies.

DAZHI FAN, BMSc; LIHONG XIN, BMSc; LI LIU, BMSc; GUOQI CAI, BMSc; Department of Epidemiology and Biostatistics, School of Public Health, Anhui Medical University; SHENGQIAN XU, PhD, Department of Rheumatism and Immunity, the First Affiliated Hospital of Anhui Medical University, Hefei, Anhui; FAMING PAN, PhD, Department of Epidemiology and Biostatistics, School of Public Health, Anhui Medical University, 81 Meishan Road, Hefei, Anhui 230032, China.

Address correspondence to F. Pan; E-mail: famingpan@ahmu.edu.cn Dazhi Fan and Lihong Xin contributed equally to this work and should be considered co-first authors.

\section{REFERENCES}

1. Liu YF, Wen CY, Tu SH. On the relationship of male sexual dysfunction and ankylosing spondylitis. J Rheumatol 2015; 42:2513-14

2. Fan D, Liu L, Ding N, Liu S, Hu Y, Cai G, et al. Male sexual dysfunction and ankylosing spondylitis: a systematic review and metaanalysis. J Rheumatol 2015;42:252-7.

3. Xu Q, Yang J, Zhang L. [Sexual dysfunction in men with ankylosing spondylitis.] [Article in Chinese] Mod Med J Chi 2007;9:63-5.

4. Pirildar T, Müezzinoğlu T, Pirildar S. Sexual function in ankylosing spondylitis: a study of 65 men. J Urol 2004;171:1598-600.

J Rheumatol 2015;42:12; doi:10.3899/jrheum.150847 